\title{
Educação Permanente em Saúde: uma estratégia de gestão para pensar, refletir e construir práticas educativas e processos de trabalhos
}

\section{Permanent Education in the Healthcare Field: a Management Strategy to Think, Reflect and Build Educational Practices and Work Processes}

\author{
Flávia Carotta \\ Fonoaudióloga. Mestre em Distúrbios da Comunicação pela Pon- \\ tifícia Universidade Católica de São Paulo. Assessora Técnica da \\ Secretaria Municipal de Saúde de Embu, SP. \\ Endereço: Rua Andronico dos Prazeres Gonçalves, 114 , Centro, CEP \\ 06804-200, Embu, SP, Brasil. \\ E-mail: flaviacarottaळyahoo.com.br

\section{Débora Kawamura} \\ Especializanda em Gestão do Trabalho e Educação na Saúde pela \\ Escola Nacional de Saúde Pública; Assistente técnico-administra- \\ tiva da Secretaria Municipal de Saúde de Embu, SP. \\ Endereço: Rua Andronico dos Prazeres Gonçalves, 114 , Centro, CEP \\ 06804-200, Embu, SP, Brasil. \\ E-mail: dekawamuraœhotmail.com

\section{Janine Salazar} \\ Graduanda na área de Recursos Humanos pela Universidade Santo \\ Amaro (Unisa). Arte-educadora da Secretaria Municipal de Saúde \\ de Embu, SP. \\ Endereço: Rua Andronico dos Prazeres Gonçalves, 114 , Centro, CEP \\ 06804-200, Embu, SP, Brasil. \\ E-mail: janesalazarळig.com.br
}

\section{Resumo}

Este trabalho relata a experiência de implantação da Política Nacional de Educação Permanente em Saúde (EPS), proposta pelo Ministério da Saúde (Portaria 198 de fevereiro de 2004) no município de Embu, Estado de São Paulo, Essa implantação foi adotada pela gestão municipal com o objetivo de identificar e definir ações educativas que qualifiquem a atenção e a gestão em saúde através da formação e do desenvolvimento dos trabalhadores do setor. A EPS trabalha com ferramentas que buscam a reflexão crítica sobre a prática cotidiana dos serviços de saúde, sendo, por si só, um processo educativo aplicado ao trabalho que possibilita mudanças nas relações, nos processos, nos atos de saúde e nas pessoas. Outras potencialidades dessa estratégia são: fortalecimento do controle social; repolitização do Sistema Único de Saúde (SUS); incentivo ao protagonismo de usuários e trabalhadores no processo saúde e doença e a produção de um impacto positivo sobre a saúde individual e coletiva da população.

Palavras-chave: Educação permanente em saúde; Formação e desenvolvimento; Gestão em saúde. 


\section{Abstract}

The present work reports the experience of the local authority of Embu, in the State of São Paulo, in the implementation of the National Policy of Permanent Health Education (PHE) proposed by the Ministry of Health. This strategy was adopted by the municipal management with the objective of identifying and defining educational actions that qualify health care and management through the education and development of the workers of the sector. PHE works with tools that aim at the critical reflection on the daily practice of the health services, being an educational process applied to work that enables changes in the relations, processes, healthcare practices and persons. Other potentialities of this strategy are: strengthening of social control; re-politicization of the Brazilian public health system (SUS); stimulation to the leading role of users and workers in the health and disease process; and production of a positive impact on the individual and collective health of the population.

Keywords: Permanent Health Education; Education and Development; Health Management.

\section{Introdução}

A Política Nacional de Educação Permanente em Saúde (EPS) lançada pelo Ministério da Saúde através da Portaria 198, de fevereiro de 2004, possibilita a identificação das necessidades de formação e de desenvolvimento dos trabalhadores da área da sáude e a construção de estratégias e processos que qualifiquem a atenção e a gestão em saúde, fortalecendo o controle social com o objetivo de produzir um impacto positivo sobre a saúde individual e coletiva da população.

Essa estratégia foi adotada pela gestão do município de Embu, São Paulo, através da formação de facilitadores de educação permanente, iniciada em 2005 e ampliada em 2006, possibilitando a criação de um Núcleo de Educação Permanente em Saúde Municipal.

\section{Justificativa}

Atualmente a qualidade na assistência à saúde e a humanização dos serviços têm ocupado espaço na agenda da gestão municipal como meta prioritária para a consolidação do Sistema Único de Saúde (SUS). A EPS trabalha com ferramentas que buscam a reflexão crítica sobre as práticas de atenção, gestão e formação, sendo, por si só, um processo educativo aplicado ao trabalho, possibilitando mudanças nas relações, nos processos, nos atos de saúde e nas pessoas e uma melhor articulação para dentro e para fora das instituições.

\section{Objetivos}

- Formar facilitadores em educação permanente em todas as unidades de saúde e na sede da secretaria.

- Criar um núcleo de educação permanente.

- Envolver gestores, trabalhadores, usuários e instituições de ensino nas discussões.

- Refletir sobre a prática e construir propostas de capacitação, sensibilização, treinamentos e outras intervenções visando a formação dos gestores, trabalhadores e usuários do SUS.

- Realizar diagnóstico e planejar as ações de saúde de acordo com as necessidades da locorregião.

- Transformar as práticas cotidianas, os processos de trabalho e as relações. 


\section{Metodologia}

O investimento com a Educação Permanente no município teve início com a formação de três facilitadores de educação permanente em saúde através do Polo de EPS da Grande São Paulo e financiamento do Ministério da Saúde em parceria com a Escola Nacional de Saúde Pública em 2005. A partir deste momento foram realizadas rodas de reflexão e discussão sobre os processos de trabalho com a participação de representantes das unidades básicas, centros de atenção à saúde da família, pronto-socorros, sede da secretaria e Conselho Municipal de Saúde. As discussões utilizavam as ferramentas apresentadas pelo Curso de Formação de Facilitadores de EPS seguindo três eixos: Análise do Contexto da Gestão e das Práticas de Saúde, Trabalho e Relações na Produção do Cuidado em Saúde e Práticas Educativas no Cotidiano do Trabalho em Saúde.

No eixo Análise do Contexto da Gestão, as rodas proporcionavam uma reflexão sobre os serviços de saúde e seus processos instaurados nos diversos níveis de atenção. Participaram representantes de unidades básicas de saúde, centros de atenção à saúde da família, pronto-socorros e usuários membros do Conselho Municipal de Saúde. Os temas abordados foram: Conceito de Saúde e Doença; Gestão de Saúde; Informação e Planejamento em Saúde; e Humanização.

No eixo Trabalho e Relações na Produção do Cuidado, o material proposto pelo curso foi aplicado com representantes da equipe de uma unidade básica de saúde, com a participação do gerente, profissionais de nível superior, auxiliar de enfermagem, recepcionista e usuário representante do Conselho Gestor da Unidade. Os temas abordados foram: Conceito de EPS; Conceito de Cuidado; Qualidade na assistência; Fluxograma analisador; Reflexão e Discussão sobre nós críticos do serviço; Referência e Contra-referência; e Trabalho em equipe.

No eixo Práticas Educativas, participaram das rodas: trabalhadores técnicos e administrativos da sede da secretaria de saúde. 0 objetivo era a discussão da agenda de cursos e capacitações propostas pelas diversas áreas programáticas e vigilância em saúde. Os principais temas abordados foram: Comunicação; Informação; Reuniões de equipe; Rede analisadora do processo de trabalho; Avaliação dos Cursos e Capacitações realizadas; Diagnóstico situacional; e Planejamento.
Em 2006, dando seqüência a formação de facilitadores, formou-se um tutor próprio do município com mais 20 facilitadores indicados pelas gerências dos serviços de saúde do município: seis unidades básicas, cinco centros de atenção à saúde da família, dois pronto-socorros, dois centros de atenção psicossociais e cinco representantes da sede da secretaria. 0 conteúdo do material proposto pelo Curso de formação em EPS foi aplicado em cada local de trabalho, disseminando o conhecimento e envolvendo novos atores.

Este grupo formou o Núcleo de EPS municipal, que ampliou a discussão sobre a implantação da Política de EPS no município.

O município pode contribuir, também, na implantação de uma Política Regional de EPS, participando efetivamente na reestruturação do Núcleo de Educação Permanente Regional, outra experiência inovadora, que reuniu gestores, trabalhadores, usuários e instituições de ensino de treze municípios da região oeste e sudoeste da Grande São Paulo para refletir sobre a EPS e propor e avaliar projetos de formação a serem encaminhados ao Pólo de EPS. O papel mais importante deste núcleo, que atravessou períodos de indefinições na Política Nacional de EPS, foi de realizar as reuniões dentro dos métodos propostos pela EPS, em rodas, e com a reflexão coletiva dos diversos segmentos participantes, levando a EPS para municípios com as mais diversas realidades.

\section{Resultados Alcançados}

Os principais resultados alcançados foram:

- 70\% dos facilitadores de EPS concluíram o curso;

- 54\% das unidades de saúde do município contam com a atuação efetiva dos facilitadores de EPS;

- Criação do Núcleo de Educação Permanente em Saúde;

- Mudanças nas estratégias de acolhimento de algumas unidades de saúde;

- Retomada das reuniões de equipe da sede da secretaria; - Criação de espaços para a reflexão do trabalho nas unidades de saúde;

- Maior participação e responsabilização dos trabalhadores;

- Melhor integração entre sede e unidades de saúde através do apoio e supervisão da equipe de educação permanente e estratégia da saúde da família; 
- Criação de instrumentos para avaliação de cursos, capacitações e eventos oferecidos pela secretaria de saúde;

- Integração da equipe de Recursos Humanos a Educação Permanente possibilitando a implementação de ações de gestão do trabalho e educação em saúde.

\section{Aprendizado com a Vivência: facilidades e dificuldades}

\section{Facilidades}

- Comprometimento e sensibilização do gestor com a estratégia da EPS;

- Comprometimento e responsabilidade dos facilitadores no desempenho de suas tarefas;

- Legitimação das reuniões e rodas de reflexão como rotina de trabalho pelo Gestor e Gerentes das Unidades;

- Possibilidade das Unidades de Saúde proporem e realizarem ações e estratégias de acordo com as necessidades da população/comunidade locorregionais.

\section{Dificuldades}

- Dificuldade dos trabalhadores em aplicar os conceitos na prática;

- Rotina diária de trabalho intensa, que dificulta a agenda de encontros da equipe e a possibilidade de aprofundar as reflexões com leituras complementares e formar grupos de estudo;

- Desmotivação de alguns trabalhadores;

- Incluir os profissionais médicos na discussão;

- Ampliar a participação dos usuários.

\section{Considerações Finais}

O município de Embu tem uma história importante com relação a propostas de formação através de reciclagens para médicos clínicos, ginecologistas e pediatras; realização de capacitações e sensibilizações para agentes comunitários de saúde, enfermagem, profissionais da saúde bucal e mental; realização de eventos como fóruns, seminários e oficinas; e a participação ativa da universidade através de pesquisas e realização de projetos. A proposta de Educação Permanente em Saúde veio ao encontro das necessidades de aperfeiçoar estes mecanismos, tornando-os mais participativos, respeitando o conhecimento dos profissionais e ampliando os espaços de aprendizagem no próprio local de trabalho.

Um dos fatores mais importantes desta proposta é a reflexão crítica dos processos de trabalho. Na avaliação dos participantes das rodas, a fala que mais se repete refere-se ao espaço propiciado para encontro da equipe e possibilidade de falar sobre os problemas, nós críticos construindo soluções coletivamente. 0 ato da assistência e as relações melhoram a partir da responsabilização de cada envolvido.

O Núcleo de Educação Permanente deverá prosseguir com as ações iniciadas no processo de formação dos facilitadores de educação permanente e realizar um Plano Municipal de Educação Permanente, seguindo as orientações e diretrizes propostas no Pacto pela Saúde, assinado pelo Município, Estado e União em outubro de 2007.

\section{Referências}

BRASIL. Ministério da Saúde. Portaria GM/MS $n^{\circ}$ 198, de 13 de fevereiro de 2004. Institui a Política Nacional de Educação Permanente em Saúde. Diário Oficial da União, Brasília, DF, 2004. Seção 1.

BRASIL. Ministério da Saúde. Portaria GM/MS $\mathrm{n}^{0} 1996$ de 20 de agosto de 2007. Dispõe sobre as diretrizes para a implementação da Política Nacional de Educação Permanente em Saúde. Diário Oficial da União, Brasília, DF, 22 ago. 2007. Seção 1.

BRASIL. Ministério da Saúde. Secretaria de Gestão do Trabalho e da Educação na Saúde. Departamento de Gestão da Educação na Saúde. A educação permanente entra na roda: pólos de educação permanente em saúde: conceitos e caminhos a percorrer. 2. ed. Brasília, DF; 2005. 